\title{
Un rechazo garante del deseo
}

\author{
Rodrigo Valetín Abínzano
}

\begin{abstract}
Resumen
En el presente trabajo indagamos la función de la anorexia en tanto garante del deseo, tomando para ello los desarrollos realizados por Lacan en los Seminarios VIII y IX. Dicha elección se debe al especial interés que tuvo para nuestra investigación examinar las referencias allí contendidas en relación al rechazo, la Versagung y al cuerpo. Para ordenar nuestro proceder, utilizamos coordenadas puntuales, las cuales hacen eco con las menciones hechas por Lacan sobre esta presentación sintomática. Las mismas son: a) la anorexia como "trastorno" de la oralidad, ligada la diferenciación entre necesidad-demanda-deseo; b) las diferencias entre el amor del narcicismo y el amor del don; c) la Versagung, entre rechazo y frustración; d) la inmersión topológica como pasión anoréxica: pasar de tres dimensiones a dos; e) algunos efectos epistémico-clínicos del objeto $a$ en la imagen especular así como el lugar del imperativo de goce. En un apartado final se encuentran conclusiones y líneas ulteriores de trabajo.
\end{abstract}

\section{Palabras clave:}

Anorexia; Lacan; Deseo; Rechazo; Inmersión; Goce.

\section{A desire's guarantor rejection}

\begin{abstract}
In the present work we investigate the function of anorexia as a guarantor of desire, taking for it the developments made by Lacan in Seminars VIII and IX. This choice is due to the special interest it had for our research to examine the references contained there in relation to the rejection, the Versagung and the body. To order our procedure, we use point coordinates, which echo with the mentions made by Lacan about this symptomatic presentation. They are: a) anorexia as a "disorder" of orality, the differentiation between need-demand-desire; b) the differences between the love of narcissism and the love of the gift; c) the Versagung,
\end{abstract}


between rejection and frustration; d) the topological immersion as an anorexic passion: going from three dimensions to two; e) some epistemic-clinical effects of the object $a$ in the mirror image as well as the place of the imperative of enjoyment. In a final section there are conclusions and further lines of work.

\title{
Keywords:
}

Anorexia; Lacan; Desire; Rejection; Immersion; Joy.

\section{Uma rejeição fiadora do desejo}

\begin{abstract}
Resumo
No presente trabalho, investigamos a função da anorexia como fiadora do desejo, partindo das elaborações de Lacan nos Seminários 8 e 9. Essa escolha deve-se ao interesse especial desta pesquisa em examinar as referências contidas ali em relação à rejeição, ao Versagung e ao corpo. Para ordenar nosso procedimento, usamos coordenadas pontuais, que ecoam as menções feitas por Lacan sobre essa apresentação sintomática. São elas: a) anorexia como uma "desordem" da oralidade, a diferenciação entre necessidade-demanda-desejo; b) as diferenças entre o amor do narcisismo e o amor da dádiva; c) o Versagung, entre a rejeição e a frustração; d) a imersão topológica como uma paixão anoréxica: indo de três dimensões a duas; e) alguns efeitos epistêmico-clínicos do objeto $a$ na imagem especular, bem como o lugar do imperativo do gozo. Na seção final, há conclusões e outras linhas futuras de trabalho.
\end{abstract}

\section{Palavras-chave:}

Anorexia; Lacan; Desejo; Rejeição; Imersão; Gozo.

\section{Un rejet garant du désir}

\section{Résumé}

Dans le présent travail, nous étudions la fonction de l'anorexie en tant que garant du désir, en nous inspirant des développements réalisés par Lacan lors des Séminaires VIII et IX. Ce choix est dû à l'intérêt particulier que notre recherche a porté à examiner les références qui y figurent en relation avec le rejet, la Versagung et le corps. Pour ordonner notre procédure, nous utilisons des coordonnées de point, qui font écho aux mentions faites par Lacan à propos de cette présentation symptomatique. Ce sont : a) l'anorexie en tant que «trouble » de l'oralité, la différenciation entre besoin-demande-désir ; b) les différences entre l'amour du narcissisme 
et l'amour du don ; c) la Versagung, entre le rejet et frustration ; d) l'immersion topologique en tant que passion anorexique : passer de trois dimensions à deux ; e) certains effets épistémico-cliniques de l'objet $a$ sur le miroir ainsi que la place de l'impératif de jouissance. La dernière section présente les conclusions et les autres axes de travail.

\section{Mots-clés :}

Anorexie ; Lacan ; Désir ; Rejet ; Immersion ; Jouissance.

\section{Introducción}

La enseñanza de Lacan hecha luz sobre muchos síntomas que interrogan a la clínica actual. Si la epidemiología revela datos que dan cuenta del crecimiento de tasas de mortalidad y morbilidad para la anorexia mental, esto no debe ser despreciado por el psicoanalista, ya que incide de modo directo en los motivos de consulta con los que se encuentra su práctica.

Desde mediados de la década del treinta, encontramos registros donde Lacan teoriza sobre la anorexia mental: las sesiones de la S.P.P. (Lacan, 1933-1950/2010, pp. 5-31) fueron una escena fecunda para el entonces joven psiquiatra, asilo del germen de las producciones luego plasmadas de modo sistematizado, como atestigua el texto "Los complejos familiares en la formación del individuo" (Lacan, 1938/2012, pp. 33-96). En esa época, el acento sobre el complejo de destete y la imposibilidad de sublimación de la imago materna tienen un lugar angular, y permiten pensar la anorexia tanto como "huelga de hambre" así como "suicidio no violento"; a su vez, Lacan le asigna en su argumentación un lugar basal (en ese caso junto con las toxicomanías y las neurosis gástricas).

La que podemos delimitar como la segunda conceptualización lacaniana de la anorexia mental, tiene comienzo en el seminario sobre la relación de objeto (Lacan, 1956-1957/2009c) y se extiende - por lo menos — hasta el seminario de los cuatro conceptos fundamentales del psicoanálisis, ya que luego Lacan hace referencias aisladas que son difíciles de ubicar como una conceptualización en sí; no obstante, hay una orientación, en los años setenta, de interrogar la vertiente ligada al goce, especialmente en su vínculo con el horror al saber (Lacan, 1973-1974, clase del 9/4/1974). En este trabajo nos centraremos en las elaboraciones realizadas por J. Lacan entre los Seminarios VIII y IX, ya que encontramos allí la antesala de producción del objeto $a$, con las modificaciones y efectos que esto tuvo en su enseñanza. Por lo desarrollado allí afirmaremos que el rechazo de la anorexia funciona como garante del deseo.

En primer lugar, dedicaremos un apartado a la anorexia como "trastorno" de la oralidad, tal como Lacan la teoriza a mediados del seminario La transferencia. Coordenada de suma importancia: el rechazo como posición de la anorexia frente 
al Otro. Las diferencias entre el amor del narcicismo y el del don serán elementales a la hora de pensar el lugar del deseo y la demanda. En relación a ello, será necesario repasar la noción de Versagung, rechazo radical pero no forclusión. Luego, abordaremos el problema del cuerpo en la anorexia mental, orientados por lo que podemos llamar "una pasión topológica": pasar de tres dimensiones a dos. Esto es denominado en topología como "inmersión”. La imagen en tanto "error" será la otra vertiente del cuerpo a interrogar, preanunciando todo lo desarrollado en $\mathrm{La}$ angustia, donde el objeto en la imagen muestra sus diferentes efectos, y donde su paradigma es lo siniestro (Lacan, 1962-1963/2009f). Para finalizar, expondremos conclusiones y futuras líneas de trabajo que hayan surgido del recorrido realizado.

\section{El deseo: más acá de la demanda}

El Seminario VIII, titulado La transferencia (Lacan, 1960-1961b/2009e) es uno de los seminarios más largos dictados por Lacan. Como refiere C. Soler, el rodeo y la pregunta ambientan toda la escena, dejando muchos más interrogantes que respuestas y donde, por momentos, no sabemos bien a dónde se dirige Lacan (Soler, 1992, pp. 16-17). Probablemente El banquete de Platón sea la parte más conocida de este seminario, ocasión donde Lacan introduce los modos del erastés y eromenos, así como también la metáfora del amor, llevándonos al núcleo duro del tema de la transferencia y de la posición del analista. Posición de sujeto, posición de deseo, compulsión a la repetición, interpretación y rememoración, son algunos de los términos que ordenan las clases posteriores al diálogo platónico y que fueron ordenadas en un gran apartado, titulado en la versión oficial como "El objeto del deseo y la dialéctica de la castración”. De éste, son las afirmaciones que Lacan hace en relación a la contratransferencia las más novedosas y subversivas, evidenciando lo absurdo de pensar, en relación al reconocimiento del inconsciente, "que por sí mismo deje el analista fuera del alcance de las pasiones" (Lacan, 1960-1961/2009e, p. 213), así como también ubicando ese deseo "más fuerte” que aquellos por los cuales el analista, eventualmente, quisiera tomar en sus brazos a un paciente o tirarlo por la ventana (Lacan, 1960-1961/2009e, p. 214).

Por la posibilidad de repensar la contratransferencia, Lacan retoma la relación de la demanda y el deseo, ya que el fin del análisis es "sacar a la luz las manifestaciones del deseo del sujeto" (Lacan, 1960-1961/2009e, p. 228). El amor y el deseo se ubican de modo diferencial en relación a la demanda: mientras que el primero lo hace más allá - de allí la afirmación de que "toda demanda es demanda de amor" - el deseo lo hace más acá.

\section{Ilustración de la discordancia y rechazo}

Lacan pregunta “¿qué es una demanda oral?” y responde automáticamente: “es la demanda de ser alimentado” (Lacan, 1960-1961/2009e, p. 231). Debido a la es- 
tructura del significante, la respuesta a dicha demanda es la demanda del Otro de dejarse alimentar. No obstante, Lacan aclara que no hay una correspondencia punto por punto entre ambas demandas, sino que hay una hiancia, un gap, un desgarro, por la existencia del deseo. ${ }^{1}$

Ese deseo que desborda el encuentro - y desencuentro - de las demandas es lo que permite que la satisfacción no sea llevada a cabo de una manera total, impidiendo la extinción deseante. Dice Lacan:

Si la demanda no se extingue, es porque este deseo la desborda, que el sujeto que tiene hambre, por el hecho de que a su demanda de ser alimentado le responde la demanda de dejarse alimentar, no se deja alimentar, y rechaza de alguna forma desaparecer como deseo por el hecho de ser satisfecho como demanda. (Lacan, 1960-1961/2009e, p. 232)

El aplastamiento de la demanda mata el deseo; por ello la hiancia mantiene tanto a uno como a otro. En esa misma línea argumentativa, Lacan introduce un punto esencial para nuestra investigación: "De ahí es de donde surgen todas esas discordancias, la más ilustrativa de las cuales es la del rechazo de dejarse alimentar en la anorexia llamada, con mayor o menor razón, mental” (Lacan, 1960-1961/2009e).

Esta última cita nos permite pensar los siguientes puntos:

- En primer lugar el carácter "discordante" que tiene el encuentro de las demandas por el deseo; inclusive deberíamos hablar de un plural en tanto son "discordancias", lo cual indica modos varios de ese desencuentro.

- El carácter ilustrativo de la anorexia mental. Esta acentuación no es azarosa en la retórica de Lacan: la anorexia le permite vislumbrar de modo claro la problemática en cuestión. En el texto "La dirección de la cura...", la anorexia le permite dar cuenta, "mejor que cualquier otra presentación", las vías de realización del ser, conocidas como "las pasiones del ser"; a saber: amor, odio e ignorancia (Lacan, 1958/2008d, p. 598). Dicho uso se sostiene, en otros, en el lugar "ejemplar" que Lacan le da a la anorexia en relación a la separación en el Seminario XI (Lacan, 1964/2009g, p. 222).

- La anorexia es el modo más ilustrativo del rechazo a la demanda de dejarse alimentar, proveniente del Otro. Esto es una orientación clínica, en tanto es el deseo del sujeto el que está en juego. No es el deseo del Otro sino su demanda.

1 Este punto es esclarecido en el seminario posterior, La identificación, donde Lacan se vale de la topología e "inventa" - ya que en topología esto no existe - la figura de dos toros abrazados para dar cuenta cómo la demanda del Otro es el deseo del sujeto y como la demanda del sujeto es el deseo del Otro (Lacan, 1961-1962, clase del 30/5/1962). 
- La insistencia en Lacan de poner en tela de juicio del adjetivo "mental" para la anorexia.

Esta implícito en toda demanda el hecho de que el sujeto no quiere que ésta sea satisfecha, ya que ello mata el deseo; en la homofonía del francés tu es le désir (tu eres el deseo) y tué le desir (muerto el deseo) se ve el carácter del deseo en tanto metonímia de la falta en ser, como Lacan lo definió unos seminarios antes. Si el deseo queda fijado a la demanda del "es eso", inevitablemente detiene su movimiento y muere. Razón por la cual, hacia el final de la clase del 15 de marzo de 1961, Lacan dirá que el deseo es aporía (Lacan, 1960-1961/2009e, p. 240), es decir: encierra en sí un carácter paradojal e insuperable.

\section{Trastorno de la oralidad}

El hecho de que la pulsión obedece a dos amos distintos (la autoconservación y la sexualidad) es una afirmación clásica freudiana de los "Tres ensayos de teoría sexual" (Freud, 1905/2007b). La demanda oral, tanto la de ser alimentado como la de dejarse alimentar, se inscriben en el hecho de que "la demanda oral tiene otro sentido además de la satisfacción del hambre. Es demanda sexual" (Lacan, 1960-1961/2009e, p. 233). La crítica lacaniana a la teoría libidinal, acompaña este resto al que las demandas no pueden responder en su totalidad y que está ligado a un excedente, el cual permite que toda satisfacción posible no se vuelva vana. El rechazo antes mencionado - el cual la anorexia ilustra - preserva la función del deseo.

Dice Lacan:

Enseguida les resultará palpable en el hecho de que ya sólo por expresarse la tendencia de la boca que tiene hambre, por esa misma boca, en una cadena significante, se introduce en ella esta posibilidad de designar el alimento que deseo. ¿Qué alimento? Lo primero que resulta de ello es que esa boca puede decir - Éste no. La negación, el desvío, el me gusta eso y ninguna otra cosa del deseo, se introduce ya aquí, y la especificidad de la dimensión del deseo salta a la vista. (Lacan, 1960-1961/2009e, p. 234)

En su conformación heterogénea, el mismo órgano da asilo a la demanda oral como a la pulsión, y en esto - dice Lacan - "reside el trastorno" (Lacan, 1960-1961/2009e). Por una cuestión estructural del lenguaje, el equívoco está a la orden del día, y responder a la demanda o creer que "el otro dice o quiere decir lo que está diciendo", es perder la brújula del deseo. Si el sujeto lograra satisfacer la necesidad, el deseo no tendría razón de ser. 


\section{Don del Otro, don del sujeto: deseo de expulsión}

Las teorizaciones de los Seminarios $I V$ y $V$ se sostienen en el influjo antropológico con el cual Lacan circunscribió a la anorexia en torno a la doctrina de la simbólica del don (Lacan, 1956-1957/2009c, pp. 186 y sigs.). Si bien esta tiene introducción ya en el primero de sus seminarios, no fue hasta el seminario de la relación de objeto que se genera una interrelación con la anorexia mental.

Homologa a la pregunta por la demanda oral aparece el interrogante de la demanda anal, donde se ubica - a diferencia de la primera - un "deseo de expulsión". La demanda oral y la anal son estructuralmente diferentes: mientras la primera estaba en relación al excedente sexual del desencuentro de demandas, en la segunda "de lo que se trata es de una disciplina de la necesidad, y la sexualización sólo se produce en el movimiento de retorno de la necesidad" (Lacan, 1960-1961/2009e). Lo importante de dicho movimiento es que legítima la necesidad como don de la madre, ya que ésta espera que el niño satisfaga sus funciones, que le regale algo. Como dijera Freud: "la caca es el primer regalo, una parte de su cuerpo de la que el lactante sólo se separa a instancias de la persona amada y con la que testimonia también su ternura sin que se lo pida" (Freud, 1917/2007a, p. 120).

La oblatividad, paradigma del fantasma obsesivo, es la ofrenda que hace la diferencia con la posición frente al Otro: si antes era una demanda al Otro - si bien también esta presente el rechazo - aquí la ecuación se invierte, porque ahora es una demanda del Otro:

El estadio anal se caracteriza por lo siguiente - el sujeto sólo satisface una necesidad para la satisfacción de otro (...) Y si puede decirse que la oblatividad está ligada a la esfera de la relación del estadio anal, es porque es un don que se le pide al sujeto (...) El deseo, literalmente, se va a la mierda. (Lacan, 1960-1961/2009e, p. 235)

¿Qué le interesa al Otro de lo que yo puedo darle? Se pregunta el sujeto ante esa demanda. El estadio oral enseña que un objeto no vale por su materia concreta, sino por el lugar que ocupa en la escala de valores que le da el Otro. De allí, aquel texto tan hermoso de Freud sobre los sueños en el folclore, donde el excremento y la caca siempre se presentan como tesoros u oro en las producciones de los soñantes (Freud, 1911/1958/2007c, pp. 177-206).

Si la oblatividad inaugura para el sujeto un circuito, es porque a partir de allí él tendrá que aportar un objeto a dicha dinámica, el cual tiene la particularidad de ser un objeto que pierde... por amor al Otro. Tal vez es menester recordar aquí la diferencia realizada por Lacan en el seminario Los escritos técnicos de Freud vinculada al amor del narcicismo y el del don: 
Aprendan a distinguir ahora el amor como pasión imaginaria del don activo que él constituye en el plano simbólico. El amor, amor de quien desea ser amado, es esencialmente una tentativa de capturar al otro en sí mismo, de capturarlo en sí mismo como objeto. (Lacan, 1953$-1954 / 2009$ a, p. 401)

El amor del narcicismo es aquí el que da cuenta de esa fractura y será vía una pérdida que se constituirá un sistema simbólico, donde un don activo permite inscribir dicha pérdida en términos de ausencia. Si dijimos antes que el amor esta más allá de la demanda, éste es el amor del don, aquel que no tiene que ver con una potencia o propiedad sino con una carencia.

En el plano de la demanda anal esto es lo que se pone a prueba. "En el nivel anal todavía más que ninguna parte, debemos ser reservados en lo que a la comprensión del otro refiere" (Lacan, 1960-1961/2009e, p. 238). El margen del deseo es lo incomprensible, y en su carácter paradójico, tiene lugar en la palabra, al mismo tiempo que no habita en ella. Por ello Lacan refiere:

Responder a la demanda de alimento, a la demanda frustrada, en un significante nutriente, deja elidido lo siguiente, que más allá de todo alimento de la palabra, de aquello de lo que el sujeto tiene verdaderamente necesidad es de lo que éste significa metonímicamente, lo cual no se encuentra en ningún punto en dicha palabra. (Lacan, 1960 $-1961 / 2009$ e, p. 240)

\section{Versagung, rechazo y frustración ${ }^{2}$}

La noción de Versagung, desarrollada al final del seminario, pone en juego la polaridad rechazo-frustración, quedando más en consonancia con el primero. Esta noción tiene un antecédete en el Seminario $I V$, donde frustración, privación y castración son trabajadas al modo de tres formas de la falta diferentes, apoyadas en una manifiesta crítica del uso de las mismas por la escuela inglesa (Lacan, 1956-1957/2009c).

En la clase del 17 de mayo de 1961, Lacan dice haberle "rogado" a su auditorio que analicen en profundidad dicho término. No hablará de la Versagung como frustración ya que "su acento se puede poner mucho más allá de toda frustración concebible y mucho más profundamente” (Lacan, 1960-1961/2009e, pp. 338-

2 Excedería a nuestra investigación la profundización que exige esta noción de filiación freudiana. Recomendamos al lector orientarse por el carácter tíquico y desencadenante de la Versagung, ambos puntos desarrollados en el artículo de Ana Paula Gianesi (2015, pp. 29-41). 
-339). ${ }^{3}$ La Versagung implica una falta de promesa, por la que se renuncia a todo. Dicha renuncia esta ligada a la estructura de la palabra, ya que la Versagung es rechazo referente al dicho (Lacan, 1960-1961/2009e).

Lacan dice que la Versagung sólo tiene lugar como mecanismo en el campo de la neurosis. Para sostener ese punto, vuelve sobre la distinción hecha en La ética del psicoanálisis, entre Das Ding y de Die Sache, donde "La Cosa” (Das Ding) en tanto real, se diferencia de "las cosas" (Die Sache) simbólicas (Lacan, 1959-1960/2009d, pp. 57-62). El carácter intraducible de la Versagung solo se hace posible dentro del campo simbólico, es decir de Die Sache, ya que es allí que emerge la dimensión significante, "que le permite al sujeto escaparse" (Lacan, 1960-1961/2009e, p. 361).

Lacan traspola la discusión a la conformación misma del dispositivo analítico:

Vamos a proseguir planteando una pregunta insidiosa - ¿en qué debe consistir la Versagung del análisis? De esto, francamente, no les he dicho mucho más, pero les pregunto - la fecunda Versagung del análisis, ¿no es esto, que el analista le rehúsa al sujeto su angustia, la suya, la del analista, y deja desnudo el lugar adonde es llamado como otro para dar la señal de angustia? (...) el lugar puro del analista, en tanto que podemos definirlo en y por el fantasma, sería el lugar del deseante puro. (Lacan, 1960-1961/2009e, p. 410)

\section{Otro cariz}

Hacia el final del seminario, Lacan volverá a mencionar a la anorexia mental. Para ello, retoma el modelo óptico, el cual desde el Seminario I, es utilizado para la formalización del estadio del espejo. El punto importante a destacar de ello, es que Lacan ubica a la imagen, la realidad - y podemos agregar al cuerpo - , en el lugar del Otro; inclusive, llega a pensar que es el analista el que debe ir al lugar de ese Otro, espejo plano en el modelo, para devolver al analizante su imagen virtual, la cual por los movimientos del espejo se va modificando. Esto es planteado manifiestamente por Lacan en "Observaciones sobre el informe de Daniel Lagache...”, único escrito en el cual se encuentre el modelo (Lacan, 1960/2008e).

Se puede dar cuenta la tensión ya que el modelo, en tanto dispositivo analógico, se convierte en el principal representante del pródromo o antesala, de toda la reversión topológica que Lacan introducirá en el seminario siguiente. El falo, que en ese momento se hace esquivo al modelo, en tanto pasa de imaginario a simbólico y de simbólico a real, necesita la negativización para inscribirse. Si bien el objeto a no esta formalizado, es la función que cumple dicha negativización la que toma ese lugar.

3 Sobral desarrolla una serie de cuestiones ligadas a este punto en su libro Madres, anorexia y feminidad. Haciendo una relectura, propone dos formas de la Versagung: una como frustración, como trasmisión de la falta en consonancia con el don de amor - , y otra como rechazo del Otro (Sobral, 2011, pp. 37-38). 
Si bien el carácter formador de la imagen en tanto Gestalt sigue estando presente, con la introducción del significante, la teorización lacaniana se desliza más a indagar en las formas de imágenes afectadas por el lenguaje que por aquellas que conservan su engañosa armonía. Dice Lacan:

Por otra parte, quizás ahora veamos mejor la verdadera función que se debe atribuir en la relación objetal al nipple. La punta del seno está también en una relación gestáltica de aislamiento respecto a un fondo, y por este hecho está en posición de exclusión con respecto a aquella relación profunda con la madre que es la del amamantamiento. De lo contrario no resultaría a menudo tan difícil hacerle atrapar al lactante la punta en cuestión. Y tal vez los fenómenos de las anorexias mentales tendrían también otro cariz. (Lacan, 1960-1961/2009e, p. 424)

La cuestión de la forma tiene un lugar importante en este desarrollo, existiendo una exclusión en el amamantamiento. También confluye en este punto, el vaivén antes planteado, en relación a la doble función del órgano. La dificultad para el lactante, habla tanto de los encuentros como de los desencuentros con la punta en cuestión, y vemos que allí Lacan vuelve a traer a la anorexia a colación. Si no fuese tan difícil atrapar el pezón, los fenómenos de las anorexias mentales tendrían otro cariz, otra forma; su presentación sería diferente. Por lo cual, podemos leer que la anorexia nuevamente le sirve a Lacan para ilustrar esa relación primera con el nipple.

También hay que hacer especial mención al hecho de que Lacan habla de "fenómenos" de las anorexias mentales, que es una orientación nosográfica muy importante, ya que introduce cómo ubicar estas presentaciones, diferenciando fenómeno y estructura.

\section{La pasión topológica de la anorexia: pasar de tres dimensio- nes a dos}

Vimos en los apartados anteriores las categorías y elementos teóricos utilizados por Lacan en el seminario sobre la transferencia, los cuales permiten pensar el lugar y función de la anorexia mental en su enseñanza.

En este apartado tendrá lugar un proceso homólogo, con una serie de elementos que nos aporta el seminario La identificación, seminario vertebrado por un marcado influjo de la topología y los usos que Lacan hizo de ella. Además de retomar sus desarrollos previos, las elaboraciones de este seminario indagan un punto crucial para la anorexia mental: el cuerpo. Si hay una enseñanza a nivel topológico de la anorexia, es que en ella anida la pasión de pasar de tres dimensiones a dos. Dicha pasión, se sostiene en destruir la profundidad, tratando de alcanzar un 
nivel lo más plano posible. Este pasaje de 3D a 2D es lo que algunos autores, como por ejemplo J. M. Vappereau, llaman “inmersión” (Vappereau, 1988/1997, pp. 40 y sigs.; 90 y sigs.), contrario al movimiento que va de pasar de 2D a 3D, conocido como "sumersión", proceso por el cual una figura - valga la redundancia - se "sumerge" en la dimensión de la profundidad, como se puede hacer con una banda de Moebius o con un Toro, pero no con una botella de Klein o un Cross cap.

Siguiendo la pista freudiana, de que hay saber en el hombre primitivo, este cuerpo en dos dimensiones es cercano a la vivencia corporal de los aborígenes de Nueva Guinea, como nos enseña M. Leenhardt: "Es un detalle que es indispensable tener presente. El canaco no ha logrado destacar del conjunto la tercera dimensión, ignora la profundidad" (Leenhardt, 1947/1961, p. 21). ${ }^{4}$ Este punto donde confluyen cuerpo e ignorancia puede ser una orientación valiosa para ulteriores investigaciones.

Lacan nos anoticia de sus estudios en topología en "Función y campo de la palabra..." cuando hace referencia al toro, "a lo que habría que recurrir, en virtud de que su exterioridad periférica y su exterioridad central no constituyen sino una única región" (Lacan, 1953/2008a, pp. 307-308). De manera gradual, empezamos a encontrarnos también en los seminarios con el modelo óptico, distintos esquemas y grafos, correspondientes estos a la topología (Darmon, 1990/2008). A pesar del avance topológico en la enseñanza de Lacan, no es hasta el seminario $\mathrm{La}$ identificación que se asienta del todo la influencia de esta rama de la geometría. Decimos esto, ya que el seminario dictado entre 1961-1962, está sostenido desde sus cimientos por el entrecruzamiento psicoanálisis-topología.

\section{Usos de la topología en psicoanálisis}

Mucho se ha dicho del uso que Lacan hacía de la topología - como por ejemplo su invención de los toros abrazados para dar cuenta de la relación de la demanda entre el sujeto y el Otro, algo que en topología no existe (Lacan, 1961-1962, clase del 30/5/1962) - pero ésta siempre tiene que ser tenida en cuenta, no como la

\footnotetext{
4 La lectura de la obra de Leenhardt fue de suma importancia para Lacan, especialmente en lo que hace a la diferenciación entre palabra y lenguaje. En "Función y campo de la palabra..." menciona Do Kamo como ejemplo del lugar trascendental de lo simbólico, desde la lógica del hombre primitivo, en la conformación del ser humano (Lacan, 1953/2008a, p. 263), siguiendo la línea de investigación estructuralista, donde se encontraba, entre otros, su amigo C. Lévi-Strauss. Referencias como la hecha por Lacan en el Seminario III, mostrando la similitud entre el pensamiento salvaje y el lenguaje schreberiano (Lacan, 1955-1956/2009b, pp. 44-45) - sin olvidar el texto de Freud sobre el sentido antitético de las palabras - son un ejemplo del influjo de esta corriente antropológica en su obra. En "La ciencia y la verdad", la discusión epistemológica tiene lugar de manera más contundente, donde el autor más criticado es L. Lévy Bruhl, quien sostenía el carácter "pre-lógico" del hombre primitivo (Lacan, 1966/2008c, p. 817). Quien este interesado en introducirse en esa línea crítica recomendamos Radin (1960) y Lévi-Strauss (1962/2014).
} 
rama matemática, sino ya como una topología "propiamente analítica", no extirpable del psicoanálisis. La teoría lacaniana se vale de la topología, entre otros recursos, para criticar y repensar las categorías temporoespaciales clásicas. De allí que las críticas puristas de autores como Sokal y Bricmont (1998/1999, pp. 35 -50) apunten a una coordenada por la cual Lacan no se interesó, ya que horizonte nunca dejó de ser clínico.

Esto se ve de manera muy clara en la presentación que estos autores le dedicaron en su libro Imposturas intelectuales:

No vamos a entrar en el debate sobre la parte propiamente psicoanalítica de sus trabajos, sino que nos limitaremos a analizar sus numerosas referencias matemáticas con el fin de demostrar que Lacan ilustra a la perfección, en diferentes pasajes de su obra, los abusos citados en la introducción. (Sokal \& Bricmont, 1998/1999, p. 35)

La oración inicial nos orienta en ubicar cuál es el error de estos autores, ya que delimitan una apropiación topológica por parte de Lacan fuera de su obra; desconocemos cuál sería la parte "no psicoanalítica" del trabajo lacaniano, por lo cual consideramos infundada dicha crítica.

Lacan comienza la clase del 2 de febrero de 1962, recapitulando algunas líneas argumentativas expuestas en su escrito "Kant con Sade" (Lacan, 1963/2008b, pp. 727-751) y desarrollos paralelos realizados en el seminario sobre la ética. Exponiendo la diferencia entre el deseo, el Wohl y el Gut, dice que, en lo referente al primero, hay algo que va más allá del confort o "la concesión alimenticia":

Esto va más lejos, hasta implicar la sed tisular misma. No olvidemos el papel, la función que doy a la anorexia mental, donde podemos sentir en los primeros efectos esta función del deseo y el papel que le di a título de ejemplo para ilustrar la distinción entre el deseo y la necesidad. (Lacan, 1961-1962, clase del 28/2/1962)

Retomemos brevemente la referencia previa para poder allanar más fácilmente el camino hacia lo que Lacan dice en relación a la anorexia. Al comienzo del escrito publicado originalmente en Critique en 1963, Lacan diferencia el wohl del Gute. Para el primero dirá "El principio de placer es la ley del bien que es el wohl, digamos el bienestar” (Lacan, 1963/2008b, p. 728), mientras que para el segundo afirma: "La búsqueda del bien sería pues un callejón sin salida, si no renaciera das Gute, el bien que es el objeto de la ley moral" para luego agregar: "Nos es indicado por la experiencia que tenemos que oír dentro de nosotros mandatos, cuyo impe- 
rativo se presenta como categórico, dicho de otra manera, incondicional" (Lacan, 1963/2008b). Das Guten quedaría del lado del imperativo del goce, en tanto el bien soberano, diferenciándose así del wohl que queda inscripto, como vimos, en el principio del placer.

La mención a la anorexia tiene, en primer término, el carácter de no olvidar cuál es el papel y la función que Lacan le atribuye en relación al deseo. Luego, anafóricamente, ubica el lugar retórico de la anorexia: "ilustra", al igual que lo había hecho en la mención que vimos en el seminario de la transferencia y "ejemplo", que será retomada en el Seminario XI, cuando la anorexia muestra el carácter "ejemplar" de la operación de causación subjetiva de la separación, en relación a la pregunta ¿Puedes perderme? (Lacan, 1964/2009g, p. 222).

\section{El error de la imagen especular}

La posibilidad de diferenciar una forma de bien que se inscribe dentro del principio de placer (wohl), de otro que tiene el carácter de imperativo, ligado al goce y al superyó (Das Guten) nos lleva a la problemática de la imagen corporal. Si hay algo que la experiencia devuelve en lo referente a la presentación sintomática de la anorexia mental, es que la perturbación se encuentra en el plano de la imagen y no en lo que hace a la oralidad. Si bien, como vimos, Lacan articula la anorexia a la esfera de la oralidad, el movimiento explicativo que hace es para ubicar el valor de la anorexia en relación al deseo. No obstante, es menester destacar que es aquí que ya encontramos el imperativo de goce puesto en la imagen del sujeto con anorexia, experiencia discursiva frecuente en las modalidades con que refieren a la imagen corporal.

En el período que nos avocamos a investigar, hay por parte de Lacan una preponderancia a acerca la anorexia mental al campo del deseo vía el rechazo. Dicha modalidad se sostendrá en los seminarios posteriores, si bien con el objeto $a$ la dimensión del goce comenzará a tener mayor protagonismo. Por una cuestión de extensión, no podemos seguir aquí dicha línea de investigación, pero la consideramos una vertiente crucial a tener en cuenta.

Efecto de sus avances epistemológicos, Lacan forjará el objeto $a$, que si bien tiene una genealogía ubicable, es algo distinto de sus antecesores. En lo que refiere al plano de la imagen, el objeto no especularizable obliga a pensar el cuerpo con un carácter diferencial, acentuando lo erróneo en su creencia:

El objeto del deseo, no tiene imagen y el impasse del fantasma neurótico es que, en su búsqueda de $a$, el objeto del deseo, encuentra $i$ de $a$. Tal es el origen de donde parte toda la dialéctica a la cual, desde el comienzo de mi enseñanza, les introduzco, a saber que la imagen especular, la comprensión especular, se 
sostiene de esto de lo que me asombro que nadie haya pensado en glosar la función que le doy: la imagen especular es un error, no es simplemente una ilusión, un señuelo de la Gestalt cautivante cuya agresividad ha marcado el acento, es profundamente un error en tanto el sujeto se desconoce allí, si me permiten la expresión, en tanto que origen del yo y su desconocimiento fundamental están aquí reunidas en l'ortographe; ${ }^{5}$ y en la medida en que el sujeto se engaña, cree que tiene frente a sí su imagen; si supiera verse, si supiera, lo que es simple verdad, que no hay más que las relaciones más deformes de ningún modo identificables, entre su lado derecho y su lado izquierdo, no soñaría en identificarse a su imagen en el espejo. (Lacan, 1961-1962, clase del 30/5/1962).

El modelo óptico, utilizado en varios pasajes del seminario La transferencia, sufre ciertas modificaciones a nivel estructural, que le obligan a cambiar su estatuto analógico por el de "esquema" (Eidelsztein, 1992/2010, pp. 25-45). El objeto no especularizable modifica la concepción de la imagen, dando cuenta su carácter de "error", es decir: que por la extracción del objeto del campo de la realidad, toda imagen tendrá una mayor o menor distorsión; dix-torsión, torsión por el decir de una realidad y un cuerpo estructurados por el lenguaje.

\section{Algunas conclusiones y líneas ulteriores de investigación}

En el presente trabajo abordamos la función de la anorexia como garante de deseo. Para ello tomamos las referencias realizadas por Lacan en los Seminarios VIII y $I X$, las cuales revestían particular interés para nuestra investigación, ya que allí encontramos la antesala de producción del objeto $a$, espacio apto para poder dar cuenta la tensión y transformación de conceptos como el objeto, el cuerpo y la realidad.

Hicimos hincapié en el carácter de rechazo de la anorexia, vía por la cual sostiene el deseo. Para ello indagamos a la anorexia como "trastorno" de la oralidad, diferenciando al deseo, entre la demanda y la necesidad. Sostenidos en ello, repasamos y diferenciamos dos modos del amor: el amor del narcicismo y el amor del don, siendo esta segunda forma la que estaría más allá de la demanda, ya que es un amor que implica una pérdida.

En consonancia con la noción de rechazo, tomamos la Versagung, abordada en el litoral de la frustración y lo propio de un rechazo radical, sin por ello ser una forclusión.

Además de su modo nítido de dar cuenta de las pasiones del ser (amor, odio e ignorancia), la anorexia tiene una pasión topológica: pasar de tres dimensiones a dos. Nos valimos para dar cuenta de ello la "inmersión" como modo de encuentro con el cuerpo para estos sujetos. Complementariamente, tenemos los desarrollos lacanianos del final del seminario sobre la identificación, donde la imagen especular es planteada

5 Equivocación/ortografía. 
como un "error", dando pie a lo que se desarrollará en las primeras clases de La angustia, donde ya con el objeto $a$ - y en contrapunto con el modelo óptico - podemos decir que toda imagen es más o menos errónea o distorsionada por estar estructurada por el lenguaje (Lacan, 1962-1963/2009f). De ello podemos concluir:

a) La anorexia, entendida como un "trastorno" de la oralidad tiene en su raíz el hecho de sostener el deseo mediante ese "trastorno". De la imposibilidad del encuentro entre la demanda del sujeto y la del Otro, surge esa hiancia que la anorexia defiende mediante el rechazo.

b) La dimensión del deseo no puede ser pensada sin su relación al amor. De allí que el amor narcisista sostenga en el plano imaginario, algo que se inscribe como pérdida en el simbólico. Si la simbólica del don es acto de una pérdida, el amor ligado al más allá de la demanda tiene esta presentación. El amor narcisista se anuda a las perturbaciones a nivel de la imagen en la anorexia, que son testimonio de la no inscripción de dicha pérdida.

c) En consonancia con el punto anterior, la Versagung, modalidad de rechazo radical pero donde no hay retorno en lo real, tiene carácter de litoral, ya que no es frustración pero tampoco forclusión.

d) La anorexia tiene una pasión topológica que podemos denominar "inmersión”. La misma es el intento de pasar de tres dimensiones a dos, eludiendo la variable de la profundidad.

e) La anorexia tiene para Lacan carácter un ilustrativo, ejemplar y fenoménico. En relación a los primeros dos, recurso retórico que hace cadena con el anaforismo ligado a la anorexia en su carácter estructurante (en este caso en relación al deseo, pero también en relación al síntoma, a la causación subjetiva y a la puesta en forma del saber inconsciente, entre otras). En segundo término (en relación a lo fenoménico), diferenciándose de una perspectiva que entienda a la anorexia como una estructura por fuera de neurosis, perversión o psicosis. La anorexia, por su carácter fenoménico, es transestructural. Característica que comparte con el fenómeno psicosomático. ${ }^{6}$

f) El saber del hombre primitivo da cuenta la relación entre el cuerpo y la ignorancia. Hay toda una línea de investigación a seguir por dicha vía, teniendo en cuenta que Lacan articula la anorexia mental con la ignorancia, el amor y el odio, las pasiones del ser.

g) Los desarrollos epistémicos de los Seminarios VIII y IX nos permiten dar cuenta los pródromos e incidencias que tuvo la modificación del estatuto del objeto en el campo de la realidad y de la imagen.

6 En otro lugar abordamos este punto. Abínzano \& Pozzobon (2018). 
h) El imperativo de goce ligado a esta presentación tiene su germen inaugural en el acercamiento realizado por Lacan entre la anorexia y la moral kantiana, a la altura del seminario sobre la identificación.

\section{Referencias bibliográficas}

Abínzano, R., \& Pozzobon, F. (2018). Elucidaciones clínicas en torno del fenómeno psicosomático y la anorexia mental en la obra de Jaques Lacan. In X Congreso Internacional de Investigación y Práctica Profesional en Psicología. XXV Jornadas de Investigación. XIV Encuentro de Investigadores en Psicología del Mercorsur. Facultad de Psicología. Buenos Aires: Universidad de Buenos Aires.

Darmon, M. (2008). Ensayos acerca de la topología lacaniana (P. Peusner, trad.). Buenos Aires: Letra Viva. (Obra original publicada en 1990)

Eidelsztein, A. (2010). Modelos, esquemas y grafos en la enseñanza de Lacan. Buenos Aires: Letra Viva. (Obra original publicada en 1992)

Freud, S. (2007a). Sobre la trasposición de la pulsión, en particular del erotismo anal. In S. Freud. Obras completas (J. L. Etcheverry, trad.) (Vol. XVII, pp. 109222). Buenos Aires: Amorrortu. (Obra original publicada en 1917)

Freud, S. (2007b). Tres ensayos de teoría sexual. In S. Freud. Obras completas (J. L. Etcheverry, trad.) (Vol. VII, pp. 177-206). Buenos Aires: Amorrortu. (Obra original publicada en 1905)

Freud, S. (1958/2007c). Sueños en el folklore. In S. Freud. Obras completas (J. L. Etcheverry, trad.) (Vol. XII, pp. 114-123). Buenos Aires: Amorrortu. (Obra original publicada en 1911)

Gianesi, A. (2015, Octubre). (Des)enlaces clínicos: breves apuntes sobre el caso de Hans. Stylus: Revista de Psicoanálisis, 31, 29-41.

Lacan, J. (1961-1962). Seminario IX: la identificación. Inédito.

Lacan, J. (1973-1974). Séminarie XXI: les non-dupes errent. Inédito.

Lacan, J. (2008a). Función y campo de la palabra y el lenguaje en psicoanálisis. In J. Lacan. Escritos 1 (T. Segovia, trad.) (pp. 231-310). Buenos Aires: Siglo XXI. (Obra original publicada en 1953)

Lacan, J. (2008b). Kant con Sade. In J. Lacan. Escritos 2 (T. Segovia, trad.) (pp. 727754). Buenos Aires: Siglo XXI. (Obra original publicada en 1963)

Lacan, J. (2008c). La ciencia y la verdad. In J. Lacan. Escritos 2 (T. Segovia, trad.) (pp. 813-834). Buenos Aires: Siglo XXI. (Obra original publicada en 1966)

Lacan, J. (2008d). La dirección de la cura y los principios de su poder. In J. Lacan. Escritos 2 (T. Segovia, trad.) (pp. 559-615). Buenos Aires: Paidós. (Obra original publicada en 1958)

Lacan, J. (2008e). Observaciones sobre el informe de Daniel Lagache: "Psicoanálisis y estructura de la personalidad”. In J. Lacan. Escritos 2 (T. Segovia, trad.) (pp. 617-651). Buenos Aires: Siglo XXI. (Obra original publicada en 1960) 
Lacan, J. (2009a). El seminario, libro I: los escritos técnicos de Freud (R. Cevasco \& V. M. Pascual, trad.). Buenos Aires: Paidós. (Obra original publicada en 1953-1954) Lacan, J. (2009b). El seminario, libro III: las psicosis (J. L. Delmont-Mauri \& D. S. Rabinovich, trad.). Buenos Aires: Paidós. (Obra original publicada en 1955-1956)

Lacan, J. (2009c). El seminario, libro IV: la relación de objeto (E. Berenguer, trad.). Buenos Aires: Paidós. (Obra original publicada en 1956-1957)

Lacan, J. (2009d). El seminario, libro VII: la ética del psicoanálisis (D. S. Rabinovich, trad.). Buenos Aires: Paidós. (Obra original publicada en 1959-1960)

Lacan, J. (2009e). El seminario, libro VIII: la transferencia (E. Berenguer, trad.). Buenos Aires: Paidós. (Obra original publicada en 1960-1961)

Lacan, J. (2009f). El seminario, libro X: la angustia (E. Berenguer, trad.). Buenos Aires: Paidós. (Obra original publicada en 1962-1963)

Lacan, J. (2009g). El seminario, libro XI: los cuatro conceptos fundamentales del psicoanálisis (J. L. Delmont-Mauri \& J. Sucre, trad.). Buenos Aires: Paidós. (Obra original publicada en 1964)

Lacan, J. (2010). Intervenciones de Lacan en la Sociedad Psicoanalítica de París. In J. Lacan. Intervenciones y textos 1 (D. S. Rabinovich, trad.) (pp. 5-31). Buenos Aires: Manantial. (Obra original publicada en 1933-1950)

Lacan, J. (2012). Los complejos familiares en la formación del individuo. In J. Lacan. Otros escritos (G. Esperanza et al., trad.) (pp. 33-96). Buenos Aires: Paidós. (Obra original publicada en 1938)

Leenhardt, M. (1961). Do Kamo. Buenos Aires: Eudeba. (Obra original publicada en 1947)

Lévi-Strauss, C. (2014). El pensamiento salvaje. Buenos Aires: FCE. (Obra original publicada en 1962)

Radin, P. (1960). El hombre primitivo como filósofo. Buenos Aires: Eudeba.

Sobral, G. (2011). Madres, anorexia y feminidad. Buenos Aires: Filigrana.

Sokal, A., \& Bricmont, J. (1999). Imposturas intelectuales. Buenos Aires: Paidós. (Obra original publicada en 1998)

Soler, C. et al. (1992). Lacan y El banquete. Buenos Aires: Manantial.

Vappereau, J.-M. (1997). Estofa: las superficies topológicas intrínsecas. Buenos Aires: Kliné. (Obra original publicada en 1988)

Recebido: 23/02/2019

Aprovado: 14/05/2019 